
A C G
Rec. Nat. Prod. 13:2 (2019) 141-155
publications

\title{
Evaluation of the Antioxidative and Anti-inflammatory Effects of the Extract of Ribes mandshuricum (Maxim.) Kom. Leaves
}

\author{
Lingyu Li $\odot^{1,2,3 \#}$, Weiwei Du $\odot^{1,2,3 \#}$ and Wei Wang $\odot^{1,2,3^{*}}$ \\ ${ }^{1}$ Key Laboratory of Forest Plant Ecology, Ministry of Education, Northeast Forestry University, \\ Hexing Road 26, 150040, Harbin, P.R. China \\ ${ }^{2}$ Engineering Research Center of Forest Bio-preparation, Ministry of Education, Northeast Forestry \\ University, Hexing Road 26, 150040, Harbin, P.R. China \\ ${ }^{3}$ State Engineering Laboratory of Bio-Resource Eco-Utilization, Northeast Forestry University, \\ Hexing Road 26, 150040, Harbin, P.R. China
}

(Received March 09, 2018; Revised June 21, 2018; Accepted July 01, 2018)

\begin{abstract}
This study was designed to investigate the antioxidative and anti-inflammatory effects of the extract of Ribes mandshuricum (Maxim.) Kom. leaves. Seven major flavonoids (rutin, hyperoside, isoquercetin, trifolin, astragalin, quercetin and kaempferol ) were successfully prepared from the Ribes mandshuricum leaves by MAEDES methods followed by X-5 macroporous resin. Then, the antioxidant activities of Ribes mandshuricum leaves flavonoids were evaluated by DPPH, ABTS and FRAP assays. We revealed that the Ribes mandshuricum leaves flavonoids had the antioxidant abilities. Finally, it was discovered that Ribes mandshuricum leaves flavonoids could effectively inhibit the NO production and increase the IL-10 cytokines production in LPS-induced RAW 264.7 cells. It suggested that the Ribes mandshuricum leaves flavonoids had the potential anti-inflammatory effects. Therefore, the major flavonoids of Ribes mandshuricum leaves have potential use as functional food or cosmetics to delay senescence, guard health and prevent chronic disease.
\end{abstract}

Keywords: Ribes mandshuricum (Maxim.) Kom.; flavonoids; antioxidant activity; RAW264.7 macrophage; antiinflammatory activity. C 2018 ACG Publications. All rights reserved.

\section{Introduction}

Ribes mandshuricum (Maxim.) Kom., also known as Manchurian currant, which belongs to Saxifragales Grossulariaceae, is one kind of deciduous shrubs [1]. Its distribution range extends across China, North Korea and Russia. It is widely cultivated in North China for urban landscaping. Its berries can be traditionally used for producing jams, jellies, teas and juices, and also used as a kind of traditional Chinese medicine called Shan-Yingtao or Denglong-guo. The berries are rich in bioactive compounds

\footnotetext{
* Corresponding author: E-Mail: wangwei19780110@,126.com; Phone:086-0451-82191387

\# These authors contributed equally to this work and should be considered co-first authors
}

The article was published by ACG Publications 
such as: vitamins, anthocyanins, phenolic acids and flavonoids. However, the leaves as the by-products of agriculture have not been fully utilized.

In our previous chemical investigation, flavonoids proved to be the main bioactive components in Ribes mandshuricum leaves for the first time [2]. Rutin, hyperoside, isoquercetin, trifolin, astragalin, quercetin and kaempferol were the most abundant flavonoids and attracted more and more interest due to their ample bioactivities. The seven components possess antioxidant activity, anti-lipid peroxidation activity, vasodilatation, anti-viral activity, antagonistic of platelet-activating factor (PAF), antiinflammatory activity, analgesic activity, hepatoprotective effect and antidepressant activity etc [3-14]. At present, there is not much research about the Ribes mandshuricum, but some plants belong to its same family have been deep researched. For instance, black currant (Ribes nigrum L.) was reported that it represent an abundant source of phytochemicals with potent antioxidant and anti-inflammatory properties [15,16]; Ribes glaciale Wall. demonstrated significant anti-inflammatory and analgesic activity [17].

In recent decades, deep eutectic solvents (DESs), environmentally friendly solvents have been dramatically expanding in popularity [18]. Studies had demonstrated that DES can be recovered and recycled and it is excellent solvent with extremely low toxicities and favorable biodegradability [19]. In many researches, a green and efficient DES-microwave-assisted extraction approach was turned to be suitable for the extraction of bioactive compounds from natural plants [20]. Thus, DES-MAE approach was chosen to extract flavonoids from Ribes mandshuricum leaves.

Based on the aforementioned, the aim of this study was to evaluate the antioxidant abilities and anti-inflammatory effects of the extract of Ribes mandshuricum leaves and provide an experimental basis for future applications.

\section{Materials and Methods}

\subsection{Plant Materials}

The leaves of Ribes mandshuricum were collected from Heilongiiang Academy of Agricultural Sciences, P.R. China, in 2016. The plant material was identified by Professor Bai-Lin Wang from Heilongjiang Academy of Agricultural Sciences, P.R. China. Then the air-dried materials were pulverized by a pulverizer (HX-200A, Yongkang, P.R. China), then sieved (80 100 mesh) and store in closed desiccator prior to use.

\subsection{Chemicals and Reagents}

Choline chloride $(\mathrm{ChCl})(>98.0 \%)$ was purchased from Aladdin Chemistry Co., Ltd. (Shanghai, P.R. China). Lactic acid (85.0-90.0\%) and ethanol were obtained from Fuchen Chemical Reagents Co. (Tianjin, China). Rutin $(>98.0 \%)$ and trifolin $(>98.0 \%)$ were purchased from Shanghai Yuanye Reagent Company (Shanghai, P.R. China). Hyperoside $(>98.0 \%)$, isoquercetin $(>98.0 \%)$, astragalin $(>98.0 \%)$, quercetin $(>98.0 \%)$ and kaempferol $(>98.0 \%)$ were obtained from Nanjing Zelang Biological Technology Co., Ltd. (Jiangsu, P.R. China). Acetonitrile and phosphoric acid were purchased from J \& K Chemical Ltd. (Beijing, P.R. China). Deionized water was purified by using a Unique-R20 waterpurification system from Research Scientific Instruments Co. (Xiamen, P.R. China). All solvents were HPLC grade. All samples were filtered through $0.45 \mu$ m nylon membranes (Millipore, P.R. USA) prior to use.

Macroporous resins (D101, AB-8, NKA-9, HPD-400, HP20, HPD-826, LSA-10 and X-5) were provided by Zhengzhou Qinshi Technology Co., Ltd. (He'nan province, P.R. China). The physical parameters of the macroporous resins used are listed in Table 1. Prior to using, macroporous resins were soaked in $95 \%$ ethanol for $24 \mathrm{~h}$ and then washed several times with deionized water. Afterwards, the macroporous resins were soaked in 5\% (mass fraction) $\mathrm{HCl}$ solution for 2 4 $\mathrm{h}$ and then washed with 
deionized water. Following, the washed macroporous resins were soaked in $2 \%$ (mass fraction) $\mathrm{NaOH}$ solution for $2 \sim 4 \mathrm{~h}$. Subsequently, the macroporous resins were washed to neutral with deionized water throughly.

Table 1. Physical parameters of the macroporous resins used

\begin{tabular}{cccccc}
\hline Trade name & Appearance & Polarity & $\begin{array}{c}\text { Surface area } \\
\left(\mathrm{m}^{2} / \mathrm{g}\right)\end{array}$ & $\begin{array}{c}\text { Average pore } \\
\text { diameter(mm) }\end{array}$ & $\begin{array}{c}\text { Particle } \\
\text { diameter(nm) }\end{array}$ \\
\hline D101 & Ivory & Non-polar & $480-520$ & $0.3-1.25$ & $13-14$ \\
NKA-9 & Ivory & Polar & $250-290$ & $0.3-1.25$ & $15.0-16.5$ \\
AB-8 & Ivory & Weak-polar & $480-520$ & $0.3-1.25$ & $13.0-14.0$ \\
HPD-400 & White & Weak-polar & $500-550$ & $0.3-1.2$ & 83 \\
HP 20 & White & Non-polar & 600 & $0.2-0.6$ & 4.6 \\
HPD-826 & White & Polar & $500-600$ & $0.3-1.25$ & $9.0-10.0$ \\
X-5 & White & Non-polar & $500-600$ & $0.3-1.25$ & $29-30$ \\
LSA-10 & Reddish & $\begin{array}{c}\text { moderately } \\
\text { polar }\end{array}$ & 550 & $0.3-1.0$ & $7-8$ \\
\hline
\end{tabular}

2,2-diphenyl-1-picrylhydrazyl (DPPH) and ascorbic acid (Vitamin C) were purchased from SigmaAldrich (St. Louis, MO, P.R. USA). The ABTS and FRAP assay kits were purchased from Beyotime Institute of Biotechnology (Jiangsu province, P.R. China).

3-[4,5-dimethylthiazole-2-yl]-2,5-diphenyltetrazolium bromide (MTT), dimethyl sulfoxide (DMSO) and lipopolysaccharide (LPS) were purchased from Sigma-Aldrich (St. Louis, MO, P.R. USA). Fetal bovine serum (FBS) was purchased from Gemini (California, P.R. USA). Dulbecco's modified Eagle's medium (DMEM) was obtained from Beijing Solarbio Science and Technology Co., Ltd. (Beijing, P.R. China). NO assay kit was purchased from Beyotime Biotechnology (Jiangsu province, P.R. China). Assay kit for interleukin (IL)-10 was obtained from Nanjing Jiancheng Bioengineering Institute (Jiangsu province, P.R. China). All remaining reagents and chemicals were analytical grade and used as received.

\subsection{Cell Culture}

The primary mouse macrophage cell line RAW 264.7 was purchased from the Type Culture Collection of Chinese Academy of Sciences (Shanghai, P.R. China). Cells were maintained in DMEM supplemented with $10 \% \mathrm{FBS}$ in a humidified incubator in an atmosphere of $5 \% \mathrm{CO}_{2}$.

\subsection{Analysis of Flavonoids by the RP-HPLC Method}

Seven flavonoids in samples were analyzed by an Agilent 1260 series Liquid Chromatography System (Agilent, Palo Alto, CA, USA) equipped with a G1311C quaternary pump, a G1316A temperature column compartment, a G1314F VWD UV detector and a G1328C manual injector. A Phenomenex Curosil-PFP reversed-phase column ( 250 x $4.6 \mathrm{~mm}$ i.d., $5 \mu \mathrm{m}$, Phenomenex, USA $)$ was used. The separation were carried out by a gradient elution with phosphoric acid/water $(0.5: 99.5, v / v)$ as solvent A and acetonitrile as B. Gradient conditions were as follows: 0-7 min, 10-15\% (B); 7-10 min , $15-17 \%$ (B); $10-25 \mathrm{~min}, 17-17 \%$ (B); $25-27 \mathrm{~min}, 17-18 \%$ (B); $27-31 \mathrm{~min}, 18-19 \%$ (B); $31-$ $34 \mathrm{~min}, 19-19 \%$ (B); 34-38 min, $19-26 \%$ (B); 38-42 min, $26-26 \%$ (B); $42-55 \mathrm{~min}, 26-50 \%$ (B) ; 55-60 min, $50-10 \%$ (B). The flow velocity of mobile phase was $0.8 \mathrm{~mL} / \mathrm{min}$. The column temperature was retained $40{ }^{\circ} \mathrm{C}$ and the injection volume was $20 \mu \mathrm{L}$. The detection wavelength was set at $360 \mathrm{~nm}$. 


\subsection{Extraction Procedure}

Microwave assisted extraction (MAE): A modified MAS- II microwave oven from Sineo Microwave Chemistry Technology CO., Ltd. (Shanghai, P.R. China) was used for microwave assisted extraction. A hole was drilled in the outer casing to mount a reflux condenser onto the oven. Another hole was drilled in the outer casing to mount agitator blade into the flask.

The pulverized leaves $(1.0 \mathrm{~g})$ and accurately measured $27 \mathrm{~mL}$ of different solvents were added to a three-necked round-bottomed flask $(100 \mathrm{~mL})$. These solvents included $\mathrm{ChCl} /$ lactic acid DES with 1:2 $\mathrm{M}$ ratio and $25 \%$ deionized water and $70 \%$ ethanol. Then, the flask was set into the microwave oven. The microwave radiation power was set to $600 \mathrm{~W}$. After extraction at $54^{\circ} \mathrm{C}$ for $10 \mathrm{~min}$, the solutions were collected, centrifuged and defined volume to $50 \mathrm{~mL}$ with deionized water. Before HPLC analysis, all extracts were filtered through $0.45 \mu \mathrm{m}$ nylon filter. All the experiments were executed in triplicate.

Heat refluxing extraction (HRE): Precisely weighed $1.00 \mathrm{~g}$ leaves and accurately measured $\mathrm{ChCl} /$ lactic acid DES ( $27 \mathrm{~mL}$ ) were put into round-bottom flask. Afterwards the round-bottom flask was placed into the water bath kettle with a reflux unit at $65^{\circ} \mathrm{C}$ for $120 \mathrm{~min}$. Before HPLC analysis, all extracts were filtered through $0.45 \mu \mathrm{m}$ nylon filter.

Ultrasound assisted extraction (UAE): Precisely weighed $1.00 \mathrm{~g}$ leaves and accurately measured $\mathrm{ChCl} /$ lactic acid DES $(27 \mathrm{~mL})$ were put into flask. Afterwards the flask was placed into the ultrasonic bath at $54^{\circ} \mathrm{C}$ for $40 \mathrm{~min}$. Before HPLC analysis, all extracts were filtered through $0.45 \mu \mathrm{m}$ nylon filter.

\subsection{Scanning Electron Microscope (SEM) Analysis}

The powder which was before and after extracted was observed under SEM (MX2600FE, Camscan, P.R. UK) for morphological characterization. Five samples of powders (untreated and residues after DES-MAE, DES-HRE, DES-UAE and 70\% ethanol-MAE) were collected, dried until constant mass and treated by spray-gold before SEM analysis.

\subsection{Preparative Enrichment and Separation of Flavonoids from DES-MAE Extraction Solution}

The preparative purification and separation of seven major flavonoids in DES-MAE extract were carried out in a column $(26 \mathrm{~mm} \times 400 \mathrm{~mm})$ wet-packed with $10 \mathrm{~g}$ different macroporous resins (D101, AB-8, NKA-9, HPD-400, HP20, HPD-826, LSA-10 and X-5). The DES-MAE extraction solution (25 $\mathrm{mL}$ ) acquired under the optimum extracting conditions flowed through the macroporous resins column at the flow velocity of $3 \mathrm{BV} / \mathrm{h}$. Adequate deionized water $(210 \mathrm{~mL})$ was used to washed the adsorbateladen column, and then $250 \mathrm{~mL}$ of $70 \%$ aqueous ethanol $(v / v)$ at the flow velocity of $6 \mathrm{BV} / \mathrm{h}$ was used for the elution. The eluents were collected and analyzed by HPLC as mentioned above. The eluents were concentrated and dried under vacuum-rotary evaporation procedure [21], and the recoveries of seven target flavonoids were counted. All experiments were performed in triplicate.

\subsection{Evaluation of Antioxidant Activities in vitro of the Extracts by Three Different Macroporous Resins}

All experiments were done under subdued light. All samples were analyzed in triplicate at six different concentrations $(2,1,0.5,0.25,0.125,0.0625 \mathrm{mg} / \mathrm{mL})$. Vitamin $\mathrm{C}$ was used as positive control.

\subsubsection{Scavenging Activity on DPPH Radical}

The free radical scavenging activity of flavonoids which were enrichment and separated from DESMAE solutions by macroporous resins (HPD-826, AB-8 and X-5) was measured by DPPH test according to the method with some adjustments [22-25]. Sample solutions (100 $\mu \mathrm{L})$ were added to 
DPPH in ethanol solution $(0.4 \mathrm{mM}, 1 \mathrm{~mL})$. Then, ethanol $(1.4 \mathrm{~mL})$ was added into the mixture. After incubation for $70 \mathrm{~min}$ at room temperature in the dark, the decrease in absorbance was measured at 517 $\mathrm{nm}$. Results were calculated as $\mathrm{IC}_{50}(50 \%$ inhibition concentration) values in $\mathrm{mg}$ extractive $/ \mathrm{mL}$ assay $(\mathrm{mg} / \mathrm{mL})$ units, which represent the amount of extractives will react with $50 \%$ of the added DPPH radicals in the total volume of the assay under these conditions [26]. The scavenging activity of each sample was calculated as follows:

$$
\text { Scavenging activity }=\left(1-A_{\text {sample }} / A_{\text {control }}\right) \times 100 \%
$$

Where $A_{\text {control }}=$ absorbance of the ethanol solution of DPPH without sample and $A_{\text {sample }}=$ absorbance of the ethanol solution of DPPH with the tested sample.

\subsubsection{Scavenging Activity on ABTS Radical}

The ABTS radical scavenging activity was determined according to the instruction of the Beyotime Institute of Biotechnology and method [22,27]. The green ABTS was produced by reacting ABTS and allowing the mixture to stand in the dark for $12 \sim 16 \mathrm{~h}$ at room temperature before use. Sample solutions $(10 \mu \mathrm{L})$ were allowed to react with $200 \mu \mathrm{L}$ of the diluted ABTS solution for $2 \sim 6 \mathrm{~min}$ in the dark. The absorbance was taken at $734 \mathrm{~nm}$.

The scavenging activity was plotted against concentration of Trolox in order to acquire the regression equation and calculate the value of samples. The final results were expressed as Trolox equivalents $\mathrm{mmol} / \mathrm{g} \mathrm{DW}$.

\subsubsection{Ferric Reducing Antioxidant Power (FRAP)}

The FRAP was determined using a total antioxidant capacity assay kit according to the instruction of the Beyotime Institute of Biotechnology and method [28, 29]. Combined stock solution consisted of detective buffer, 2, 4, 6-tripyridyl-s-triazine (TPTZ) solution, TPTZ dilution. The working solution was made up by mixing TPTZ solution, detective buffer and TPTZ dilution in a ratio of 1:1:10 $(v / v / v)$, respectively. The working solution was kept at $37^{\circ} \mathrm{C}$ before starting to use. The sample solution $(5 \mu \mathrm{L})$ was mixed with $180 \mu \mathrm{L}$ of FRAP working solution and maintained at $37^{\circ} \mathrm{C}$ for $5 \mathrm{~min}$. The absorbance was taken at $593 \mathrm{~nm}$. The standard curve was prepared using $\mathrm{FeSO}_{4}$ ranging from 0.15 to $1.5 \mathrm{mM}$. The final results were expressed as $\mathrm{FeSO}_{4}$ equivalents $\mathrm{mmol} / \mathrm{g} \mathrm{DW}$.

\subsection{Anti-inflammatory Activity Detection}

\subsubsection{MTT Cell Viability Assay}

The RAW 264.7 cells $\left(5 \times 10^{4}\right.$ cells/well in 96 -well plates) were incubated at overnight. The cells were treated with/without extract (500-15.625 $\mu \mathrm{g} / \mathrm{mL}$ ) and dexamethasone (DXM) $20 \mu \mathrm{g} / \mathrm{mL}$ was used as a positive control. After incubation at $37^{\circ} \mathrm{C}\left(5 \% \mathrm{CO}_{2}\right)$ for $24 \mathrm{~h}, 20 \mu \mathrm{L}$ MTT $(5 \mathrm{mg} / \mathrm{mL}$ in PBS) was added and incubated at $37^{\circ} \mathrm{C}\left(5 \% \mathrm{CO}_{2}\right)$ for another $4 \mathrm{~h}$. The medium was removed and $150 \mu \mathrm{L}$ DMSO was added to dissolve the formazan cyristals. The plates were oscillated for $10 \mathrm{~min}$. The optical density of each well was measured at $490 \mathrm{~nm}$ using a microplate reader.

\subsubsection{Determination of Nitric Oxide Production}

The RAW 264.7 cells $\left(2.5 \times 10^{5}\right.$ cells/well in 24 -well plates) were incubated at overnight. Cells were stimulated with LPS $(1 \mu \mathrm{g} / \mathrm{mL})$ for $24 \mathrm{~h}$. Then, the cells were treated with/without extract $(400-12.5$ $\mu \mathrm{g} / \mathrm{mL}$ ) and dexamethasone (DXM) $20 \mu \mathrm{g} / \mathrm{mL}$ and incubated at $37^{\circ} \mathrm{C}\left(5 \% \mathrm{CO}_{2}\right)$ for $24 \mathrm{~h}$. And then, the nitrite production in the medium was determined on the basis of the Griess reaction. Each culture supernatant $(50 \mu \mathrm{L})$ mingled with Griess reagent I $(50 \mu \mathrm{L})$ and Griess reagent II $(50 \mu \mathrm{L})$ and the 
absorbance were detected at $540 \mathrm{~nm}$ using a microplate reader. Finally, the quantity of nitrite was measured from a sodium nitrite standard curve.

\subsubsection{ELISA for IL-10 Cytokines Detection}

The RAW 264.7 cells $\left(2.5 \times 10^{5}\right.$ cells/well in 24 -well plates $)$ were incubated at overnight. Cells were stimulated with LPS $(1 \mu \mathrm{g} / \mathrm{mL})$ for $24 \mathrm{~h}$. Then, the cells were treated with/without extract $(400-12.5 \mu \mathrm{g}$ $\mathrm{mL}$ ) and dexamethasone (DXM) $20 \mu \mathrm{g} / \mathrm{mL}$ and incubated at $37^{\circ} \mathrm{C}\left(5 \% \mathrm{CO}_{2}\right)$ for $24 \mathrm{~h}$. Then, the release of IL-10 in supernatant was determined by ELISA kit according to the manufacturer's protocol of the Nanjing JianCheng bioengineering Institute.

\subsection{Statistical Analysis}

The experimental data were statistically analyzed using the Origin 9.0. The experimental results in the tables and figures were formulated as average \pm standard deviation $( \pm \mathrm{SD})$.

\section{Results and discussion}

\subsection{Comparison of different extraction methods}

Figure 1 showed the HPLC chromatograms of the seven target standard substances mixture (Figure 1A) and extracting solutions by DES-MAE method (Figure 1B). In order to prove the yields of seven target flavonoids by using DES-MAE, a comparison was made between the proposed DES-MAE approach and the conventional DES-UAE and DES-HRE methods regarding their performances of rutin, hyperoside, isoquercetin, trifolin, astragalin, quercetin and kaempferol extraction from Ribes mandshuricum leaves were performed (Figure 2). The material residues after EtOH-MAE, DES-HRE, DES-UAE and DES-MAE were examined by SEM to study the effect of the different extraction methods on the physical structure of plant materials (Figure 3).

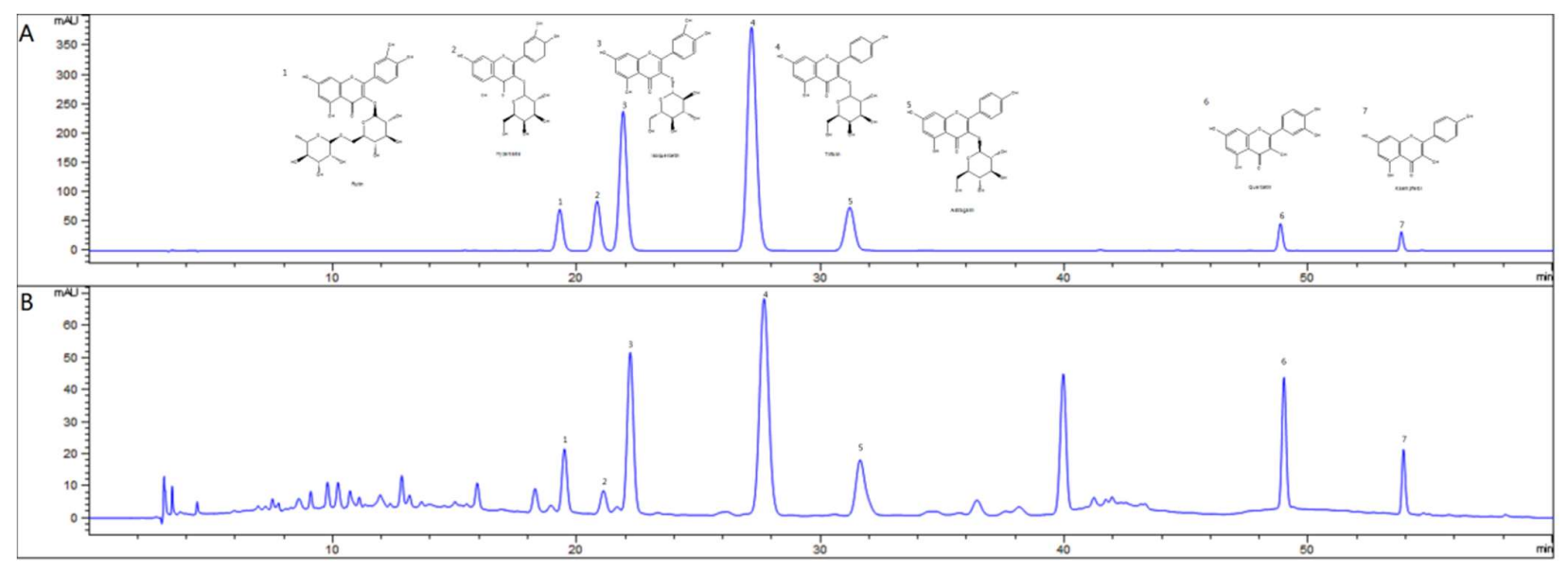

Figure 1. HPLC chromatograms of standard mixture (A) and extracts in Ribes mandshuricum leaves (B) for (1) Rutin, (2) Hyperoside, (3) Isoquercetin, (4) Trifolin, (5) Astragalin, (6) Quercetin, (7) Kaempferol. 
Compared with the leaves powder (Figure 3A ), obvious fractural changes in the material residues surface morphology became clear after microwave irradiation energy (Figure 3B and Figure 3E) and ultrasound treatment (Figure 3D); while almost no severe fracture was observed passed the heat refluxing extraction (Figure 3C). Compared Figure 3B with Figure 3E, much more fractural changes in the material residues surface morphology were appeared extracted by deep-eutectic solvent than ethanol. This phenomenon was coincided well with the experimental results in Figure 2. The yield of all seven target flavonoids using MAE method was higher than those using HRE and UAE. What's more, the yields of seven major flavonoids extract by deep-eutectic solvent were higher than those extract by ethanol. The results suggest that microwave treatment influences the structure of the plant cell due to the internal pressure increase and the sudden temperature rise [30]. During the fracture process, a rapid exudation of the major bioactive compounds within the plant cell into the peripheral solvents takes place. This mechanism of MAE based on exposing the bioactive compound to the solvent through plant cell rupture was different from that of HRE which depends on a series of penetration-dissolution process to bring bioactive compound to the solvent from the cell [31]. In this experiment, the efficiency of UAE was lower than MAE. Above all, the DES-MAE was suitable to extract seven target flavonoids from Ribes mandshuricum leaves.

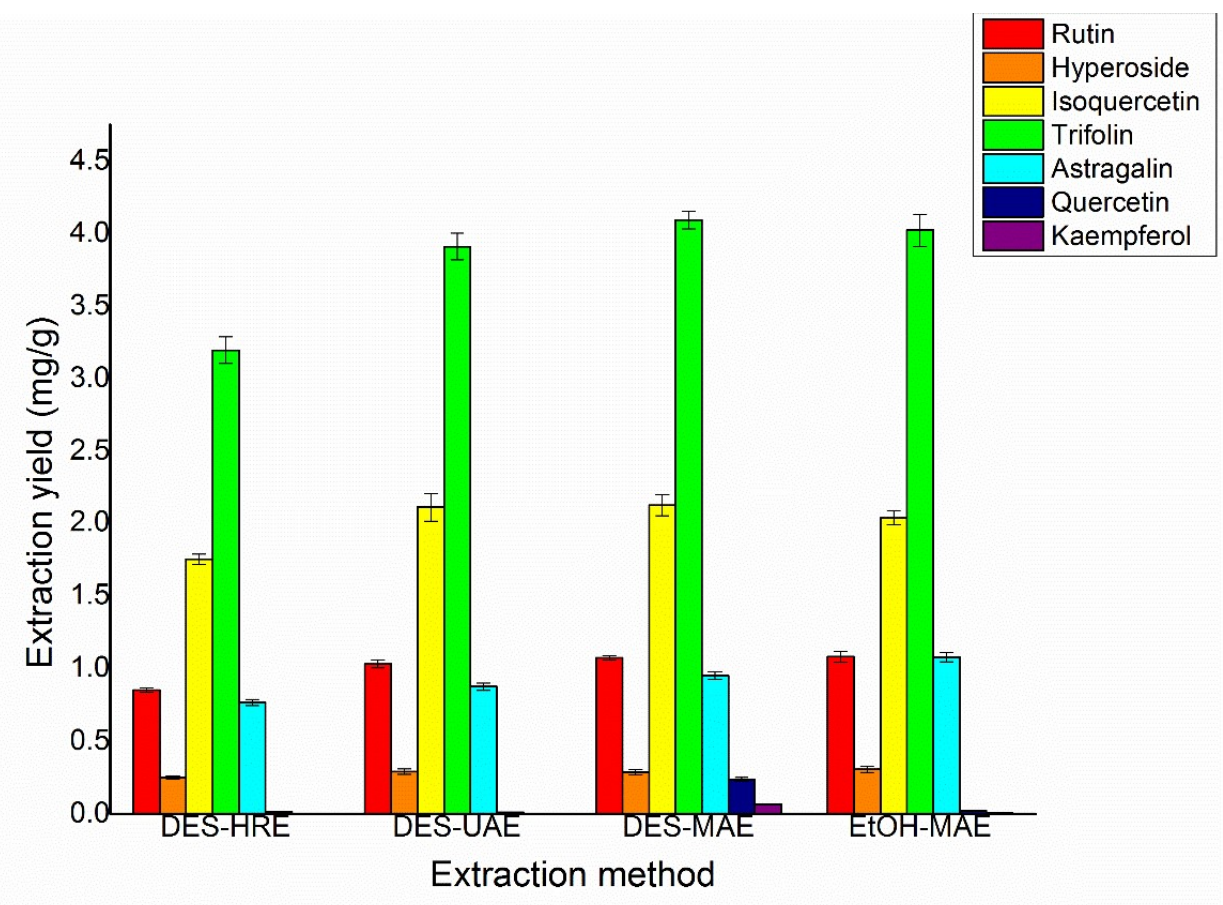

Figure 2. Comparison of different extraction method on the extraction yields of rutin, hyperoside, isoquercetin, trifolin, astragalin, quercetin and kaempferol 


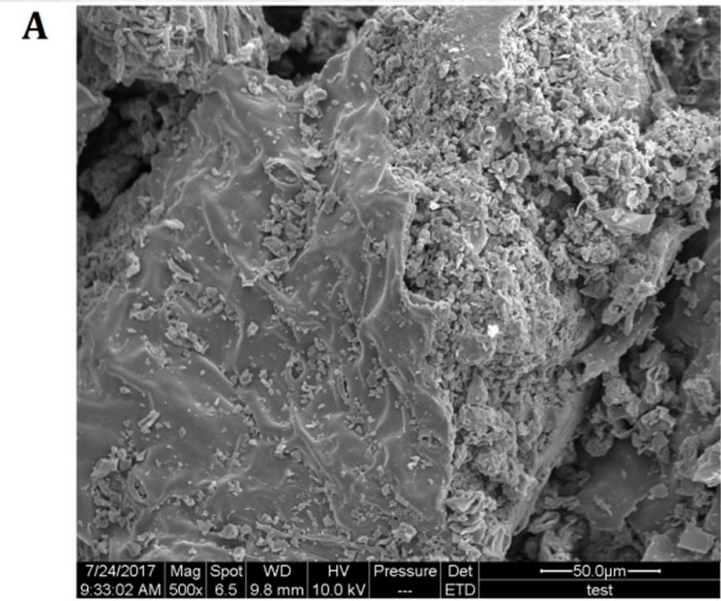

B

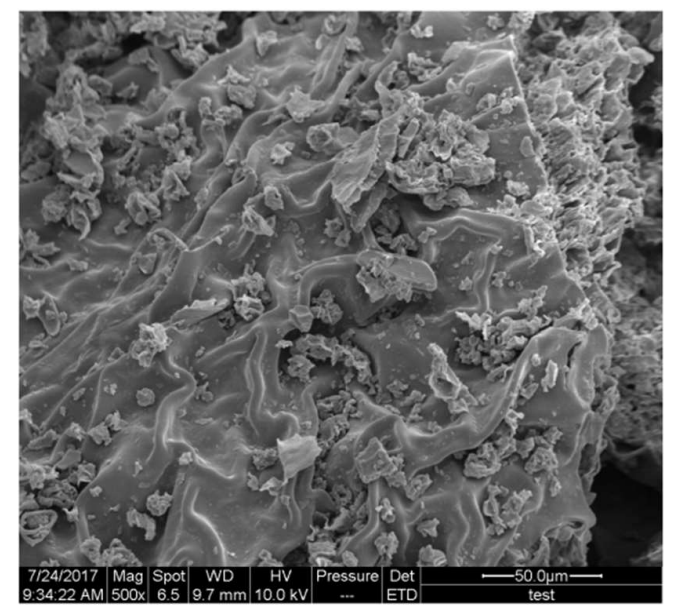

C
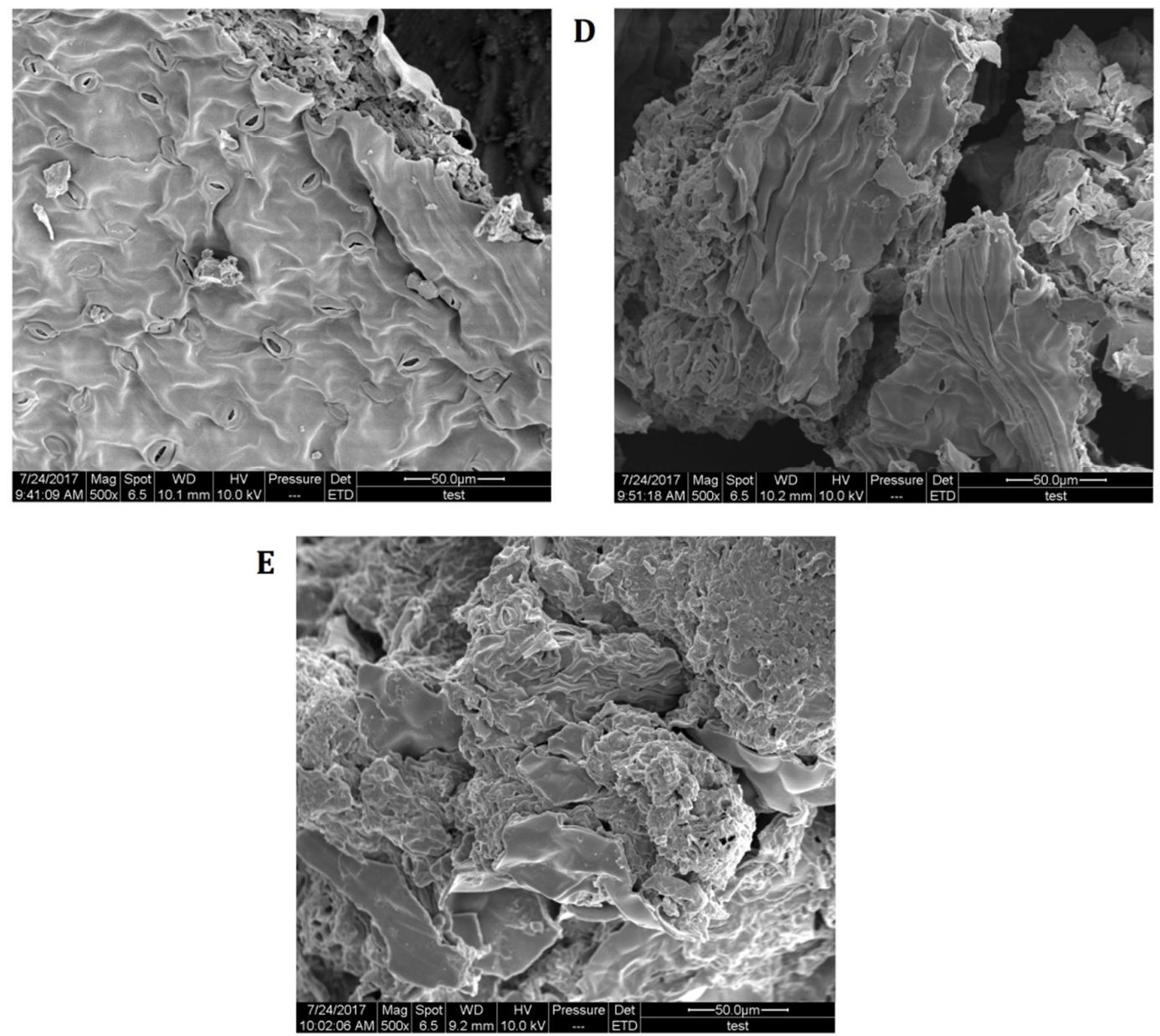

Figure 3. Scanning electron microscope images of Ribes mandshuricum leaves powder before (A) and after extraction by $70 \%$ ethanol solution microwave assisted extraction (B), DES-HRE (C), DES-UAE (D) and DES-MAE (E). 


\subsection{Preparative Enrichment and Separation of Seven Target Flavonoids from DES Extraction Solution}

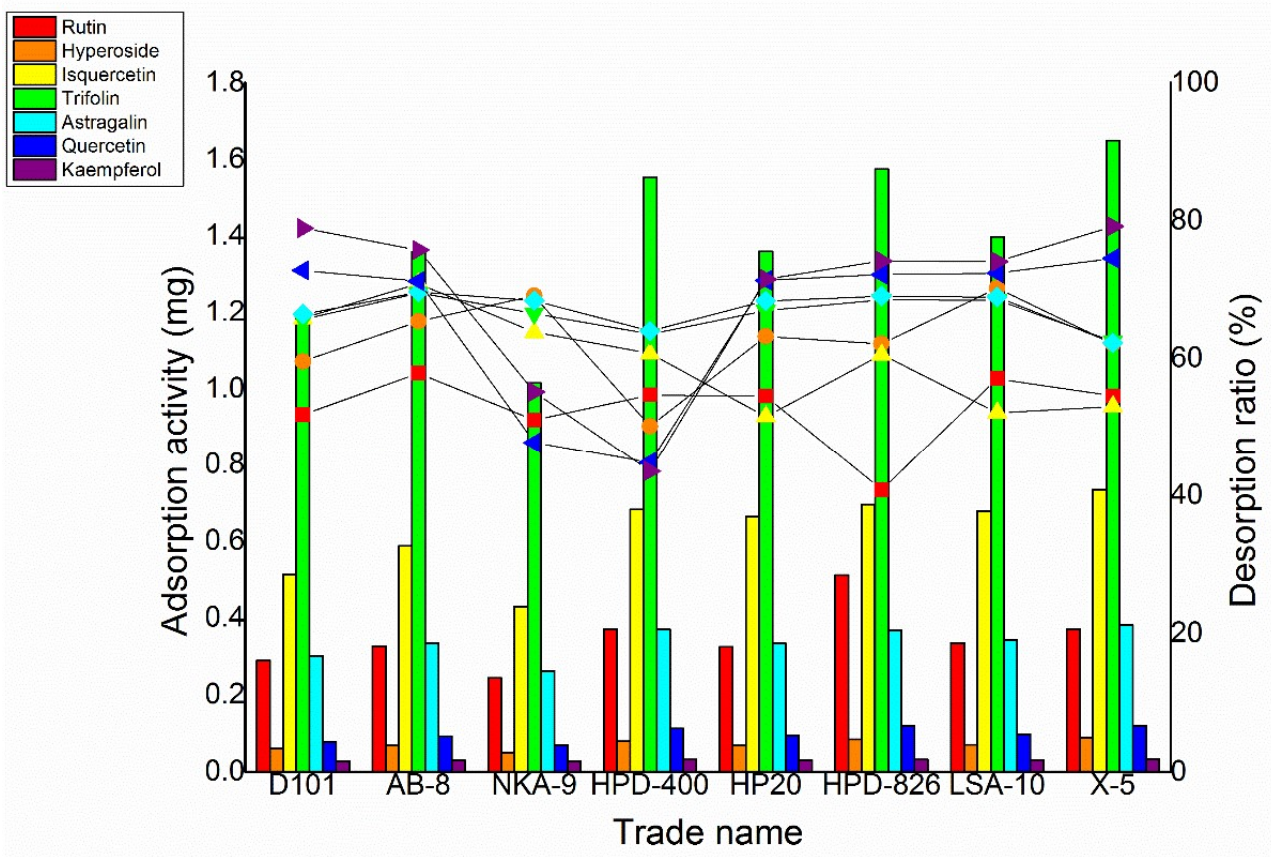

Figure 4. Adsorption capacity and desorption ratio of rutin, hyperoside, isoquercetin, trifolin, astragalin, quercetin and kaempferol using eight different macroporous resins

In this experiment, eight kinds of macroporous resins were used to directly enrich and separate seven target flavonoids from DES extraction solution. Static adsorption and desorption tests were executed in order to select the suitable macroporous resins. The absorption capacities and desorption ratios of the macroporous resins were shown in Figure. 4. Compared with other macroporous resins, HPD-826, AB-8 and X-5 resin were chosen that had a much higher adsorption capacity and the higher desorption ratio for the following enrichment and separation. The enrichment results of rutin, hyperoside, isoquercetin, trifolin, astragalin, quercetin and kaempferol from DES extraction solution with three macroporous resins were shown in Table 2.

\subsection{Antioxidant Activity}

In order to choose the most suitable macroporous resin, DPPH, ABTS and FRAP assays were taken to evaluate the antioxidant activity of Ribes mandshuricum leaves' DES extraction solutions that enriched and separated by HPD-826, AB-8 and X-5 resins. The results of antioxidant activity with different extracts after enrichment and separation were shown in Table 3 . The results suggested that values of antioxidant activity measured by three different methods were consistent and feasible. While the highest antioxidant activities in the DPPH, ABTS and FRAP assays were acquired with the extract that enriched and separated by X-5 resin. 
Antioxidative and anti-inflammatory effects of the extract of Ribes mandshuricum

Table 2. The enrichment results of seven target compounds with three macroporous resins column

\begin{tabular}{|c|c|c|c|c|}
\hline $\begin{array}{l}\text { Trade } \\
\text { name }\end{array}$ & Mass of extracts (mg/g DW) & Composition & Contents $(\%)$ & $\begin{array}{l}\text { Recovery } \\
\text { yields }(\%)\end{array}$ \\
\hline \multirow{7}{*}{ HPD-826 } & \multirow{7}{*}{222.00} & Rutin & 1.85 & 56.13 \\
\hline & & Hyperoside & 0.49 & 57.44 \\
\hline & & Isoquercetin & 3.42 & 57.37 \\
\hline & & Trifolin & 7.52 & 59.98 \\
\hline & & Astragalin & 1.82 & 60.38 \\
\hline & & Quercetin & 0.79 & 87.03 \\
\hline & & Kaempferol & 0.21 & 81.84 \\
\hline \multirow{7}{*}{ AB-8 } & \multirow{7}{*}{194.00} & Rutin & 2.21 & 76.81 \\
\hline & & Hyperoside & 0.61 & 81.05 \\
\hline & & Isoquercetin & 3.50 & 67.06 \\
\hline & & Trifolin & 6.97 & 63.52 \\
\hline & & Astragalin & 1.97 & 74.56 \\
\hline & & Quercetin & 0.41 & 51.39 \\
\hline & & Kaempferol & 0.10 & 44.54 \\
\hline \multirow{7}{*}{$\mathrm{X}-5$} & \multirow{7}{*}{291.70} & Rutin & 3.45 & 79.64 \\
\hline & & Hyperoside & 1.00 & 88.08 \\
\hline & & Isoquercetin & 6.39 & 81.37 \\
\hline & & Trifolin & 14.35 & 87.02 \\
\hline & & Astragalin & 3.46 & 87.13 \\
\hline & & Quercetin & 1.17 & 97.36 \\
\hline & & Kaempferol & 0.34 & 99.39 \\
\hline
\end{tabular}

Table 3. Comparison of antioxidant activity with different extracts after enrichment and separation

\begin{tabular}{cccc}
\hline Trade name & $\begin{array}{c}\text { DPPH IC } 50 \\
(\mathrm{mg} / \mathrm{mL})\end{array}$ & $\begin{array}{c}\text { ABTS } \\
(\mathrm{mmol} / \mathrm{g} \text { Trolox })\end{array}$ & $\begin{array}{c}\text { FRAP } \\
\left(\mathrm{mmol} / \mathrm{g} \mathrm{FeSO}_{4} \cdot 7 \mathrm{H}_{2} \mathrm{O}\right)\end{array}$ \\
\hline HPD-826 & 0.384 & 0.403 & 0.548 \\
AB-8 & 0.207 & 0.374 & 0.772 \\
X-5 & 0.189 & 0.467 & 0.957 \\
$\mathrm{~V}_{\mathrm{C}}$ & 0.084 & 1.146 & 3.188 \\
\hline
\end{tabular}

DPPH radical scavenging activities of the extracts enriched and separated by macroporous resins were expressed as $\mathrm{IC}_{50}$ values. The order of the macroporous resin type of the samples according to antioxidant capacities for DES-MAE extracts based on their $\mathrm{IC}_{50}$ values was X-5 > AB-8 > HPD-826. The value was in $\mathrm{mg}$ extractive $/ \mathrm{mL}$ assay $(\mathrm{mg} / \mathrm{mL})$ unit.

ABTS radical scavenging capacities of extracts enriched and separated by macroporous resins were expressed as Trolox equivalents $\mathrm{mmol} / \mathrm{g} \mathrm{DW}$. The order of the macroporous resin type of the samples according to antioxidant capacities for DES-MAE extracts was X-5 > HPD-826 > AB-8.

In the FRAP method, the ferric reducing antioxidant power was expressed as $\mathrm{FeSO}_{4}$ equivalent $\mathrm{mmol} / \mathrm{g}$ DW. The order of the macroporous resin type of the samples according to antioxidant capacities for DES-MAE extracts was X-5 > AB-8 > HPD-826.

Although the results of three methods were not identical, it was clear that the X-5 resin was the most suitable macroporous resin to directly enrich and separate seven target flavonoids from DES extraction solution. In addition, compared with Vitamin C, the Ribes mandshuricum leaves flavonoids had considerable antioxidant abilities. 


\subsection{In vitro Anti-inflammatory Activity}

\subsubsection{Effect of Extract on RAW 264.7 Cell Viability}

To determine the viability of RAW 264.7 cells in the presence of X-5 resin purified extract and the positive control (DXM), cells were incubated for $24 \mathrm{~h}$ with the extract/DXM at a range of concentrations $(400-12.5 \mu \mathrm{g} / \mathrm{mL})$. The cell viability was measured by MTT assay. The results were shown in Figure 5 . Obviously, all the cell viabilities were $>80 \%$. It suggested that the extract was suitable for subsequent NO inhibition research.

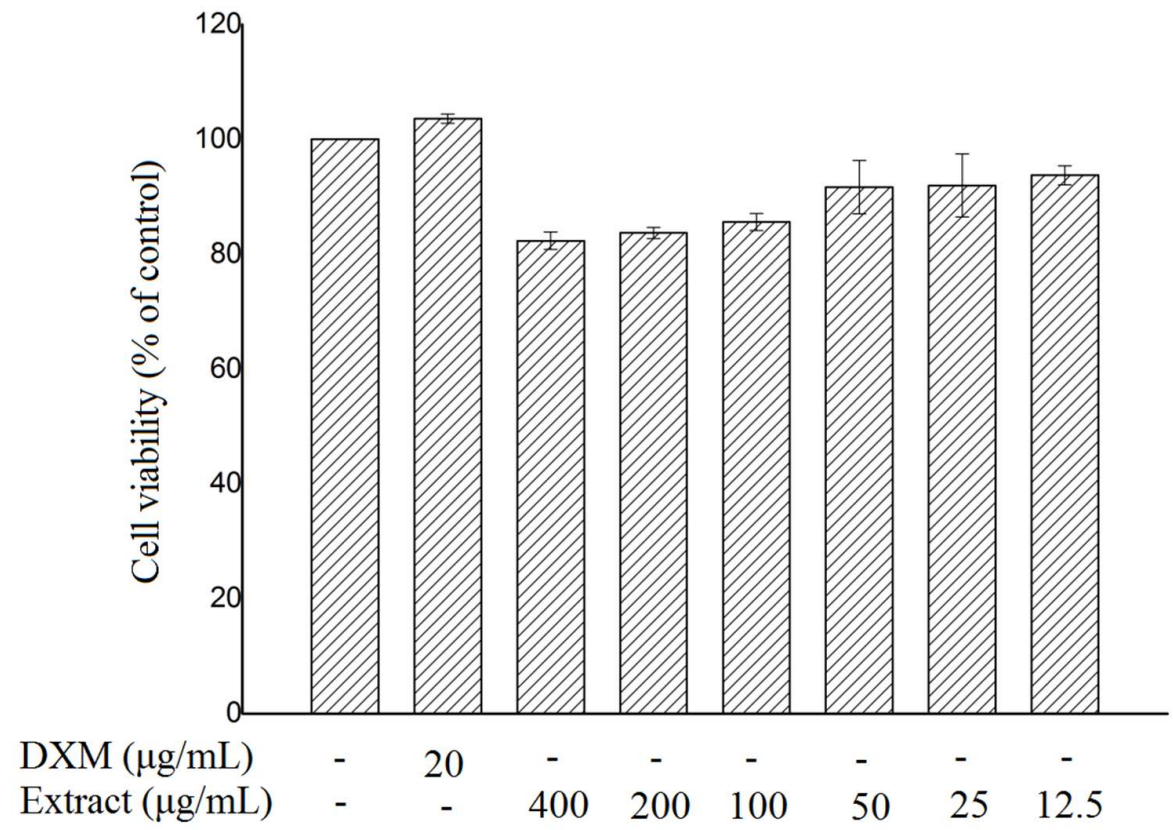

Figure 5. Effect of the Ribes mandshuricum leaves extract on the viability of RAW 264.7 cells. RAW 264.7 cells were treated with various concentrations of Ribes mandshuricum leaves extract or DXM for $24 \mathrm{~h}$. The values are mean of three replicate determinations $(\mathrm{n}=3) \pm$ standard deviation. Bars having different letters are significantly different $(p<0.05)$

\subsubsection{NO Quantification}

As a kind of significant signal transduction medium, nitric oxide (NO) play an important role in the immune system [32]. The excessive and uncontrolled production of NO can be harmful and results in various inflammatory diseases. NO was recognized as a mediator and regulator in the pathological reactions, particularly in acute inflammatory responses [33]. Analysis of the release of NO by activated macrophages can reflex the effects of the extract of Ribes mandshuricum leaves on immune function.

In this experiment, the effect of the extract of Ribes mandshuricum leaves on the production of the macrophage-activating factor NO of RAW 264.7 cells was determined by Griess assay. As shown in Figure 6, the LPS treatment resulted in an increased NO production in RAW 264.7 cells. Co-treatment with the Ribes mandshuricum leaves extract or positive control drug DXM could effectively inhibit the NO production in a dose-dependent manner. The results indicated that the leaves extract may act as an efficient anti-inflammatory agents via inhibiting the production of NO. 


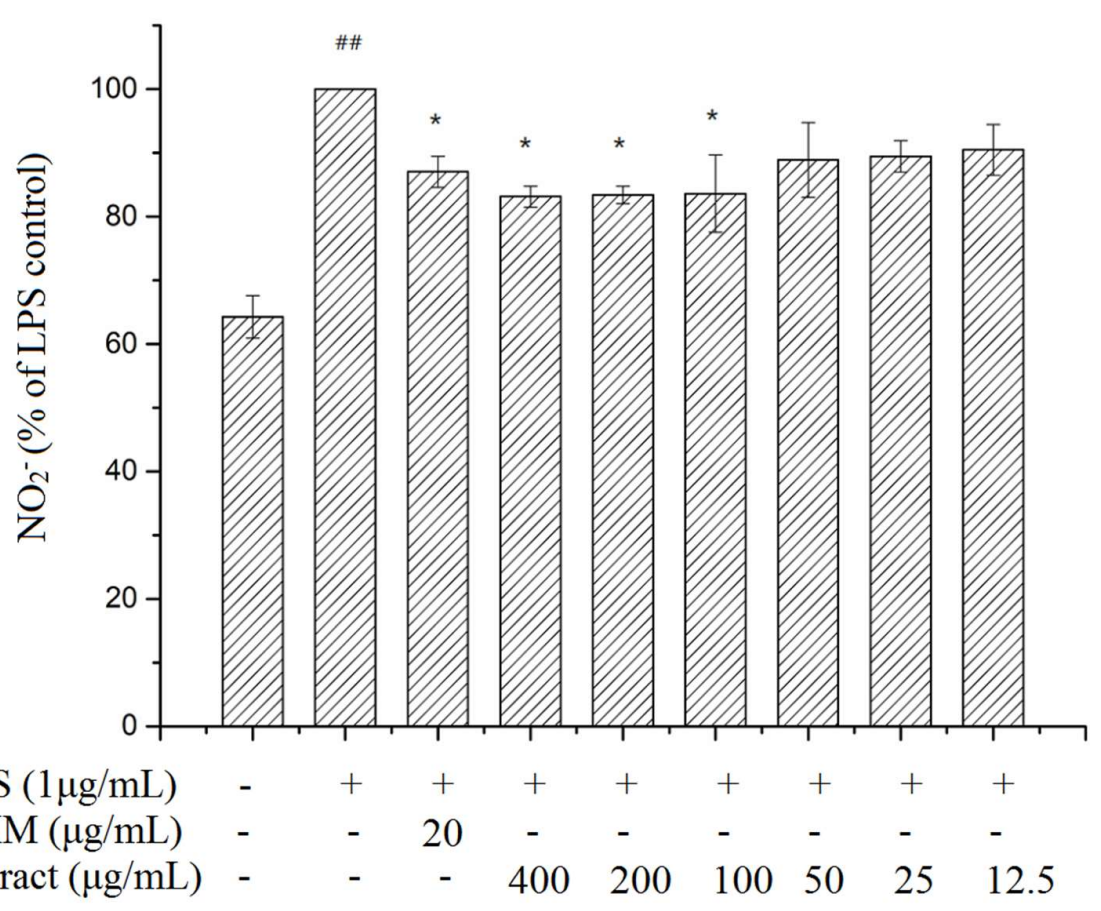

Figure 6. Inhibitory effect of Ribes mandshuricum leaves extract on NO production by LPSstimulated RAW 264.7 cells. RAW 264.7 cells were stimulated with $1 \mu \mathrm{g} / \mathrm{mL}$ of LPS. Values are mean of three replicate determinations $(n=3) \pm$ standard deviation. Bars having different letters are significantly different $(p<0.05) \#$

\#Data are expressed as the mean \pm SD of three independent experiments. ${ }^{\#} \mathrm{P}<0.01$ vs control, $\mathrm{P}<0.05$ and ${ }^{* *} \mathrm{P}<0.01$ vs LPS $1 \mu \mathrm{g} / \mathrm{mL}$. The same as below.

\subsubsection{IL-10 Cytokines Production}

IL-10 is an important cytokine whose biological function is a key to the regulation of the degree and duration of inflammatory response. IL-10 is known to act as a potent anti-inflammatory cytokine in conditioning the activation and function of innate and Ag-specific immune cells, it selectively stems the expression of pro-inflammatory genes encoding cytokines (TNF- $\alpha$, IL-6 and IL-1 $\beta$ ) and chemokines (IL-8, MCP-1, MIP-2and MIP-10) in myeloid cells [34]. As shown in Figure 7, the result revealed that the Ribes mandshuricum leaves extract could significantly increase the IL-10 cytokines production in a dose-dependent manner. This made us to the conclusion that the Ribes mandshuricum leaves extract could possess anti-inflammatory effect. 


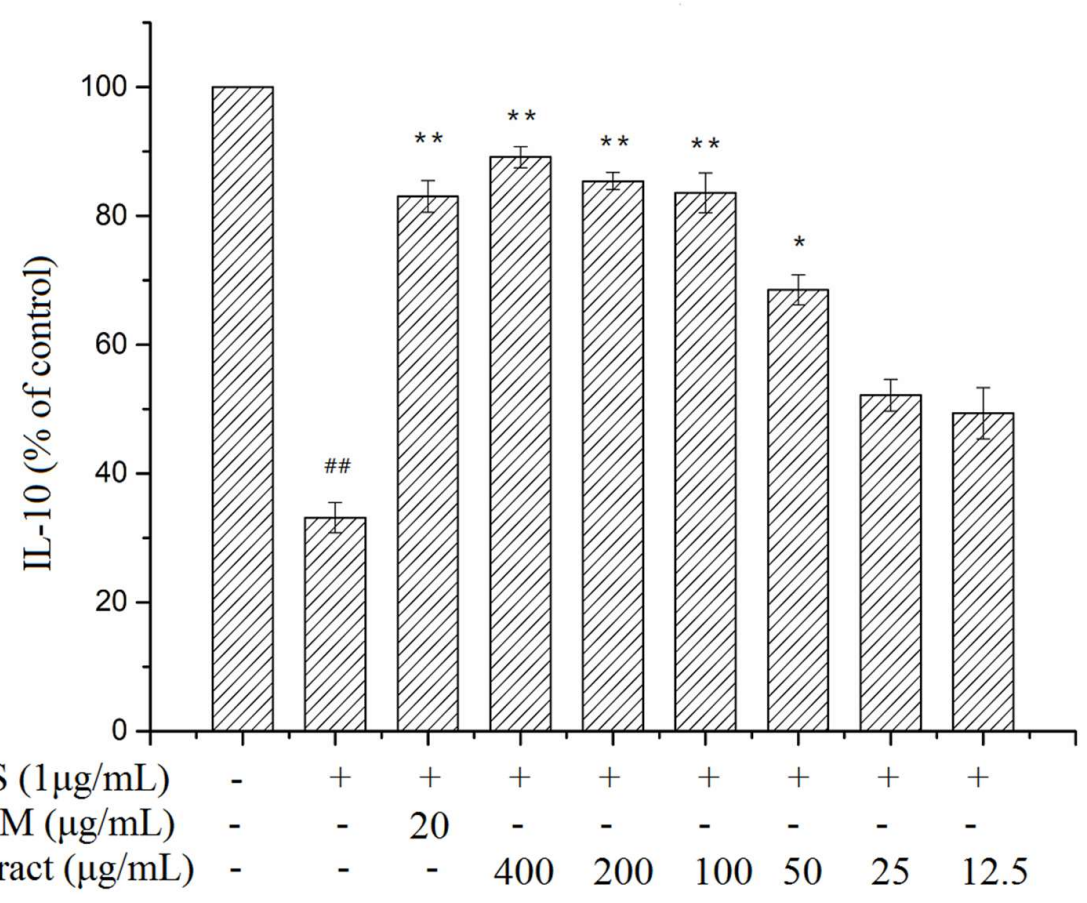

Figure 7. Effect of Ribes mandshuricum leaves extract on IL10 cytokine production by LPSstimulated RAW 264.7 cells. RAW 264.7 cells were stimulated with $1 \mu \mathrm{g} / \mathrm{mL}$ of LPS. Values are mean of three replicate determinations $(n=3) \pm$ standard deviation. Bars having different letters are significantly different $(p<0.05) \#$ \#Data are expressed as the mean $\pm \mathrm{SD}$ of three independent experiments. ${ }^{\#} \mathrm{P}<0.01$ vs control, ${ }^{*}$ $\mathrm{P}<0.05$ and ${ }^{* *} \mathrm{P}<0.01$ vs LPS $1 \mu \mathrm{g} / \mathrm{mL}$. The same as below.

\section{Conclusion}

In summary, the seven major flavonoids (rutin, hyperoside, isoquercetin, trifolin, astragalin, quercetin and kaempferol) were successfully prepared from the Ribes mandshuricum leaves by MAEDES methods followed by X-5 macroporous resin. In this study, the antioxidant activities of the extract were evaluated by DPPH, ABTS and FRAP assays. We revealed that the extract had the ability of antioxidant. In addition, the extract could effectively inhibit the NO production and increase the IL-10 cytokines production in LPS-induced RAW 264.7 cells. It suggested that the extract had the potential anti-inflammatory effects. This paper indicated that the extract of Ribes mandshuricum leaves have potential uses as functional food or cosmetics to delay senescence, guard health and prevent chronic diseases. In addition, the results of this study also indicated the need for further phytochemical investigation of Ribes mandshuricum.

\section{Acknowledgments}

The authors gratefully acknowledge the fund of National Key R\&D Program of China (2016YFD0600805) and Fundamental Research Funds for the Central Universities (2572017EA03, 2572014EA03 and DL13CA10). 


\section{ORCID}

Lingyu Li: 0000-0002-8862-5499

Weiwei Du: $0000-0003-3572-7114$

Wei Wang: $\underline{0000-0002-1722-9288}$

\section{References}

[1] D. Tomaszewski and J. Zieliński (2014). Epicuticular wax structures on stems and comparison between stems and leaves - A survey, Flora 209, 215-232.

[2] A. Nowak, A. Czyzowska, M. Efenberger and L. Krala (2016). Polyphenolic extracts of cherry (Prunus cerasus L.) and blackcurrant (Ribes nigrum L.) leaves as natural preservatives in meat products, Food Microbiol. 59, 142-149.

[3] A. Bispo da Silva, P.L. Cerqueira Coelho, J. Alves Oliveira Amparo, M.M. Alves de Almeida Carneiro, J.M. Pereira Borges, C. Dos Santos Souza, M.F. Dias Costa, M. Mecha, C. Guaza Rodriguez, V.D. Amaral da Silva and S. Lima Costa (2017). The flavonoid rutin modulates microglial/macrophage activation to a CD150/CD206 M2 phenotype, Chem. Biol. Interact. 274, 89-99.

[4] I.M. Chung, J.J. Lim, M.S. Ahn, H.N. Jeong, T.J. An and S.H. Kim (2016). Comparative phenolic compound profiles and antioxidative activity of the fruit, leaves, and roots of Korean ginseng (Panax ginseng Meyer) according to cultivation years, J. Ginseng Res. 40, 68-75.

[5] J.M. Cruz-Zuniga, H. Soto-Valdez, E. Peralta, A.M. Mendoza-Wilson, M.R. Robles-Burgueno, R. Auras and N. Gamez-Meza (2016). Development of an antioxidant biomaterial by promoting the deglycosylation of rutin to isoquercetin and quercetin, Food Chem. 204, 420-426.

[6] H. Iskender, E. Dokumacioglu, T.M. Sen, I. Ince, Y. Kanbay and S. Saral (2017). The effect of hesperidin and quercetin on oxidative stress, NF-kappaB and SIRT1 levels in a STZ-induced experimental diabetes model, Biomed. Pharmacother. 90, 500-508.

[7] E. Kashafi, M. Moradzadeh, A. Mohamadkhani and S. Erfanian (2017). Kaempferol increases apoptosis in human cervical cancer HeLa cells via PI3K/AKT and telomerase pathways, Biomed. Pharmacother. 89, 573-577.

[8] M.J. Kim, S.B. Kwon, M.S. Kim, S.W. Jin, H.W. Ryu, S.R. Oh and D.Y. Yoon (2016). Trifolin induces apoptosis via extrinsic and intrinsic pathways in the NCI-H460 human non-small cell lung-cancer cell line, Phytomedicine 23, 998-1004.

[9] F. Li, D. Liang, Z. Yang, T. Wang, W. Wang, X. Song, M. Guo, E. Zhou, D. Li, Y. Cao and N. Zhang (2013). Astragalin suppresses inflammatory responses via down-regulation of NF-kappaB signaling pathway in lipopolysaccharide-induced mastitis in a murine model, Int. Immunopharmacol. 17, 478-482.

[10] F. Lin, X. Luo, A. Tsun, Z. Li, D. Li and B. Li (2015). Kaempferol enhances the suppressive function of Treg cells by inhibiting FOXP3 phosphorylation, Int. Immunopharmacol.28, 859-865.

[11] Z. Ma, T. Piao, Y. Wang and J. Liu (2015). Astragalin inhibits IL-1 $\beta$-induced inflammatory mediators production in human osteoarthritis chondrocyte by inhibiting NF- $\mathrm{B}$ and MAPK activation, Int. Immunopharmacol. 25, 83-87.

[12] J.Y. Park, X. Han, M.J. Piao, M.C. Oh, P.M. Fernando, K.A. Kang, Y.S. Ryu, U. Jung, I.G. Kim and J.W. Hyun (2016). Hyperoside induces endogenous antioxidant system to alleviate oxidative stress, $J$. Cancer Prev. 21, 41-47.

[13] L.W. Soromou, N. Chen, L. Jiang, M. Huo, M. Wei, X. Chu, F.M. Millimouno, H. Feng, Y. Sidime and X. Deng (2012). Astragalin attenuates lipopolysaccharide-induced inflammatory responses by downregulating NF-kappaB signaling pathway, Biochem. Biophys. Res. Commun. 419, 256-261.

[14] J. Zhu, H. Tang, Z. Zhang, Y. Zhang, C. Qiu, L. Zhang, P. Huang and F. Li (2017). Kaempferol slows intervertebral disc degeneration by modifying LPS-induced osteogenesis/adipogenesis imbalance and inflammation response in BMSCs, Int. Immunopharmacol. 43, 236-242.

[15] V. Nour, I. Trandafir and S. Cosmulescu (2014). Antioxidant capacity, phenolic compounds and minerals content of blackcurrant (Ribes nigrum L.) leaves as influenced by harvesting date and extraction method, Ind. Crops Prod.53, 133-139.

[16] V. Nour, I. Trandafir and M.E. Ionica (2011). Ascorbic acid, anthocyanins, organic acids and mineral content of some black and red currant cultivars, Fruits 66, 353-362.

[17] Y. Li, D. Yang, S. Xiang and G. Li (2013). Different responses in leaf pigments and leaf mass per area to altitude between evergreen and deciduous woody species, Aust. J. Bot. 61, 424.

[18] M. Cvjetko Bubalo, N. Curko, M. Tomasevic, K. Kovacevic Ganic and I. Radojcic Redovnikovic (2016). Green extraction of grape skin phenolics by using deep eutectic solvents, Food Chem. 200, 159-166. 
[19] Y. Huang, F. Feng, J. Jiang, Y. Qiao, T. Wu, J. Voglmeir and Z.G. Chen (2017). Green and efficient extraction of rutin from tartary buckwheat hull by using natural deep eutectic solvents, Food Chem. 221, 1400-1405.

[20] Q. Cui, X. Peng, X.H. Yao, Z.F. Wei, M. Luo, W. Wang, C.J. Zhao, Y.J. Fu and Y.G. Zu (2015). Deep eutectic solvent-based microwave-assisted extraction of genistin, genistein and apigenin from pigeon pea roots, Sep. Purif. Technol. 150, 63-72.

[21] B. Liu, B. Dong, X. Yuan, Q. Kuang, Q. Zhao, M. Yang, J. Liu and B. Zhao (2016). Enrichment and separation of chlorogenic acid from the extract of Eupatorium adenophorum Spreng by macroporous resin, J. Chromatogr. B: Anal. Technol. Biomed. Life Sci. 1008, 58-64.

[22] P.S. Chiang, D.J. Lee, C.G. Whiteley and C.Y. Huang (2017). Extracting antioxidant phenolic compounds from compressional-puffing pretreated Pinus morrisonicola: Effects of operational parameters, kinetics and characterization, J. Taiwan Inst. Chem. Eng. 75, 70-76.

[23] A.L. Fogarasi, S. Kun, G. Tanko, E. Stefanovits-Banyai and B. Hegyesne-Vecseri (2015). A comparative assessment of antioxidant properties, total phenolic content of einkorn, wheat, barley and their malts, Food Chem.167, 1-6.

[24] V. Mareček, A. Mikyška, D. Hampel, P. Čejka, J. Neuwirthová, A. Malachová and R. Cerkal (2017). ABTS and DPPH methods as a tool for studying antioxidant capacity of spring barley and malt, J. Cereal Sci. 73, 40-45.

[25] D.T. Tembo, M.J. Holmes and L.J. Marshall (2017). Effect of thermal treatment and storage on bioactive compounds, organic acids and antioxidant activity of baobab fruit (Adansonia digitata) pulp from Malawi, J. Food Compos. Anal. 58, 40-51.

[26] T. Hofmann, E. Nebehaj and L. Albert (2016). Antioxidant properties and detailed polyphenol profiling of European hornbeam (Carpinus betulus L.) leaves by multiple antioxidant capacity assays and highperformance liquid chromatography/multistage electrospray mass spectro-metry, Ind. Crops Prod. 87, 340-349.

[27] Y. Kong, Z.-F. Wei, Y.-J. Fu, C.-B. Gu, C.-J. Zhao, X.-H. Yao and T. Efferth (2011). Negative-pressure cavitation extraction of cajaninstilbene acid and pinostrobin from pigeon pea [Cajanus cajan (L.) Millsp.] leaves and evaluation of antioxidant activity, Food Chem. 128, 596-605.

[28] J. Luo, L. Li and L. Kong (2012). Preparative separation of phenylpropenoid glycerides from the bulbs of Lilium lancifolium by high-speed counter-current chromatography and evaluation of their antioxidant activities, Food Chem. 131, 1056-1062.

[29] L.L. Sun, W. Gao, M.M. Zhang, C. Li, A.G. Wang, Y.L. Su and T.F. Ji (2014). Composition and antioxidant activity of the anthocyanins of the fruit of Berberis heteropoda Schrenk, Molecules. 19, 19078-19096.

[30] H.Y. Zhou and C.Z. Liu (2006). Microwave-assisted extraction of solanesol from tobacco leaves, $J$. Chromatogr. A.1129, 135-139.

[31] W. Liu, Y. Fu, Y. Zu, Y. Kong, L. Zhang, B. Zu and T. Efferth (2009). Negative-pressure cavitation extraction for the determination of flavonoids in pigeon pea leaves by liquid chromatography-tandem mass spectrometry, J. Chromatogr. A 1216, 3841-3850.

[32] X. Liu, J. Xie, S. Jia, L. Huang, Z. Wang, C. Li and M. Xie (2017). Immunomodulatory effects of an acetylated Cyclocarya paliurus polysaccharide on murine macrophages RAW264.7, Int. J. Biol. Macromol. 98, 576-581.

[33] J. Lee, K. Sowndhararajan, M. Kim, J. Kim, D. Kim, S. Kim, G.Y. Kim, S. Kim and J.W. Jhoo (2014). Antioxidant, inhibition of alpha-glucosidase and suppression of nitric oxide production in LPS-induced murine macrophages by different fractions of Actinidia arguta stem, Saudi J. Biol. Sci. 21, 532-538.

[34] A.M. Ajayi, D.T.O. Martins, S.O. Balogun, R.G. Oliveira, S.D. Ascencio, I.M. Soares, R.D.S. Barbosa and O.G. Ademowo (2017). Ocimum gratissimum L. leaf flavonoid-rich fraction suppress LPS-induced inflammatory response in RAW 264.7 macrophages and peritonitis in mice, J. Ethnopharmacol. 204, 169-178.

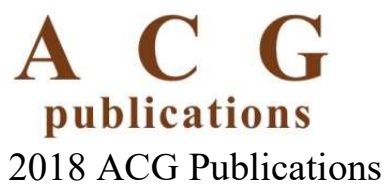

